TP Periodica Polytechnica Civil Engineering

62(4), pp. 986-991, 2018

https://doi.org/10.3311/PPci.11618

Creative Commons Attribution (i)

RESEARCH ARTICLE

\section{Moisture Transport in Cellular Concrete Walls with the Connector for Thermal Insulation}

\author{
Tomasz Steidl ${ }^{1 *}$, Paweł Krause ${ }^{1}$
}

Received 19 October 2017; Revised 24 March 2018; Accepted 10 June 2018

\begin{abstract}
The paper presents the results of in-situ research studies and hygrothermal simulations for a fragment of prefabricated cellular concrete wall, insulated with Styrofoam, allowing for two types of external plasters. The disruption of heat and mass transfer is effected by the connector for thermal insulation mounted in the layer of cellular concrete. The carried out research studies and simulations have demonstrated that the impact of the insulation connector with a steel core is observed only locally, but its destructive impact should not be ignored.
\end{abstract}

\section{Keywords}

water transport in porous materials, cellular concrete, mechanical connectors, modeling the coupled heat and mass flow, diagnosis of wall moisture content

\footnotetext{
1 Department of Building Engineering and Building Physics,

Faculty of Civil Engineering,

Silesian University of Technology

44-100 Gliwice, Poland

*Corresponding author, email: tomasz.steidl@polsl.pl
}

\section{Introduction}

The authors of the present work analyzed the impact of high initial moisture level of cellular concrete walls on their drying rate as well as the dependence of that process on the diffusion resistance of external plastering at the disruption places (connectors for thermal insulation) and outside them. The carried out analysis was made for two-dimensional modeling of a solid envelope, which, to some extent, simplified the problem of heat and mass flow through the building elements. The moisture level of external walls has a considerable impact on the demand of heating energy delivered to buildings [1], [2], [6], [9], [13]. By means of calculations and modeling of the two-dimensional transport of moisture in building envelopes, we can carry out more precise analyses involving envelope non-homogeneity or e.g. work execution imperfections. Such an approach was presented in the publications [3], [4], [5], [7], [8], [10], [11], [12], [14].

The drying process of walls having raised initial mass moisture content depends on various factors, including also local disruptions. The mentioned disruptions occur when we apply mechanical connectors of high thermal conductivity penetrating the insulation material (connectors with a steel core).

The disruptions caused by mechanical connectors result in the condensation of water vapour on connector walls. The volume and character of the formed condensate depends on the material solution applied for the connector, the wall or thermal insulation. In effect, we are faced with disturbed transport and migration of moisture in the envelope structure in the vicinity of the connector. At the places where point thermal bridges occur, structural material of the wall or the interior of the rooms may be damaged.

Local disturbances of moisture transport may result from the applied design solutions, work execution imperfections left after the execution of an investment project, or they can be related with building operation and maintenance. When analyzing the above issue, we are faced with a question whether the disruption of moisture transport effected by mechanical connectors for a cellular concrete wall and insulated in the ETICS system on the basis of expanded polystyrene will bring about any relevant local changes involving the transport of moisture. 
The ultimate objective of the carried out simulations is to be able to determine the impact of the applied type of insulation material and external plaster in the ETICS system on the local changes of moisture level of cellular concrete in the immediate vicinity of the imperfections, as e.g. steel anchors.

\section{Research programme}

The test stand was set up in a laboratory of the Faculty of Civil Engineering of the Silesian University of Technology in Gliwice (Poland). The research model was made in the way imitating a two-layer wall - Fig.1. External walls were made from cellular concrete of the thermal conductivity index of $\lambda=0.11 \mathrm{~W} / \mathrm{mK}$. The insulation layer in the ETICS system was made up by EPS Styrofoam of the thermal conductivity index of $\lambda=0.045 \mathrm{~W} / \mathrm{mK}$ and the thickness of $5 \mathrm{~cm}, 10 \mathrm{~cm}$ and $15 \mathrm{~cm}$. The research model was placed on a platform made from a Europallet enclosed on both sides with $18 \mathrm{~mm}$ thick OSB boards with the insulation made from $10 \mathrm{~cm}$ thick XPS extruded polystyrene. The top was finished with a structure covered by two layers of thermal insulation from EPS polystyrene $10 \mathrm{~cm}$ thick (external insulation) and $5 \mathrm{~cm}$ thick (internal insulation).

Apart from adhesive mortar, the Styrofoam was additionally fixed to the wall by means of plastic mechanical connectors with a steel core of $\lambda=50.0 \mathrm{~W} / \mathrm{mK}$. For the applied mechanical connectors and for the accepted thickness values of thermal insulation, we defined the range of temperature disturbances on the external wall surface, effected by the penetration of the insulation by the adjacent connectors. Following the impact analysis, the minimum distance of $17 \mathrm{~cm}$ between the connectors was accepted. The anchoring depth of the connectors was $6 \mathrm{~cm}$.

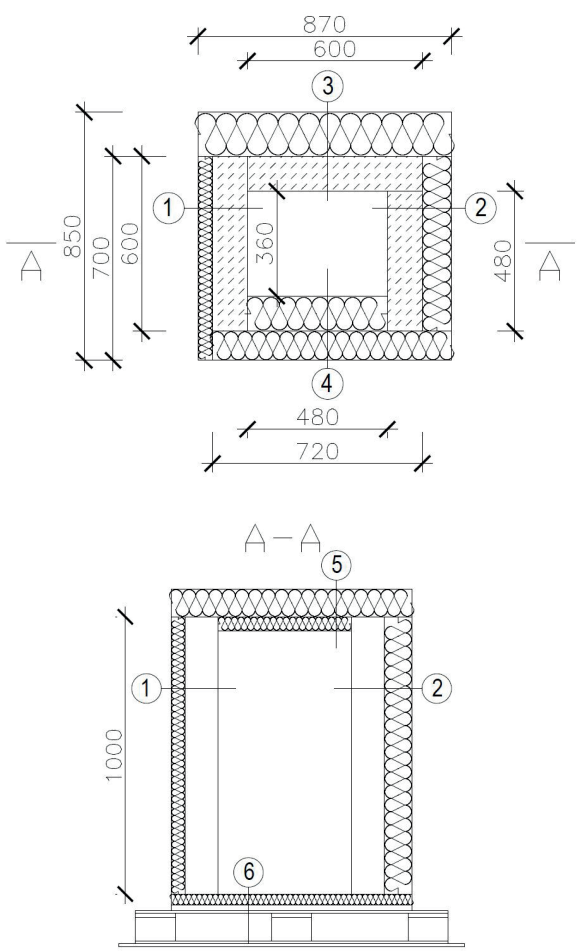

Fig. 1 Research model of the two-layer wall
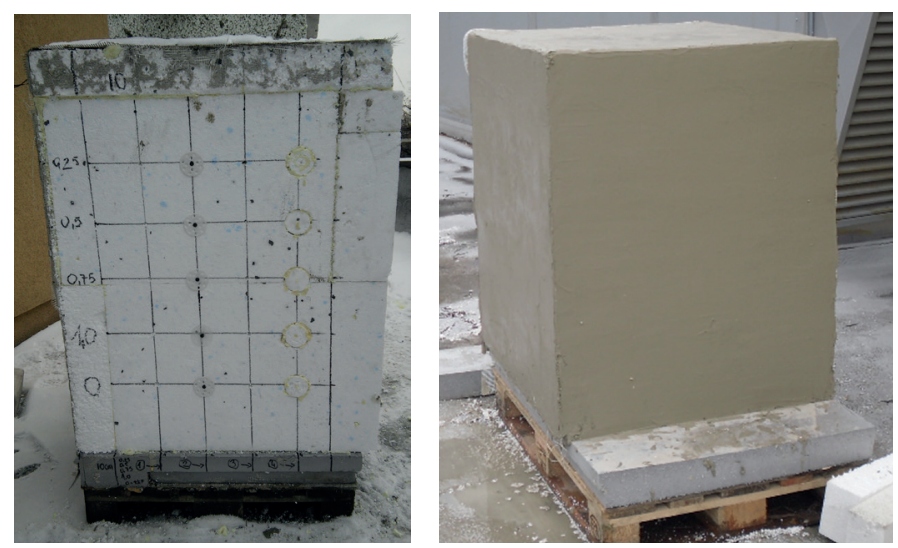

Fig. 2 View of the tested wall at the test stand
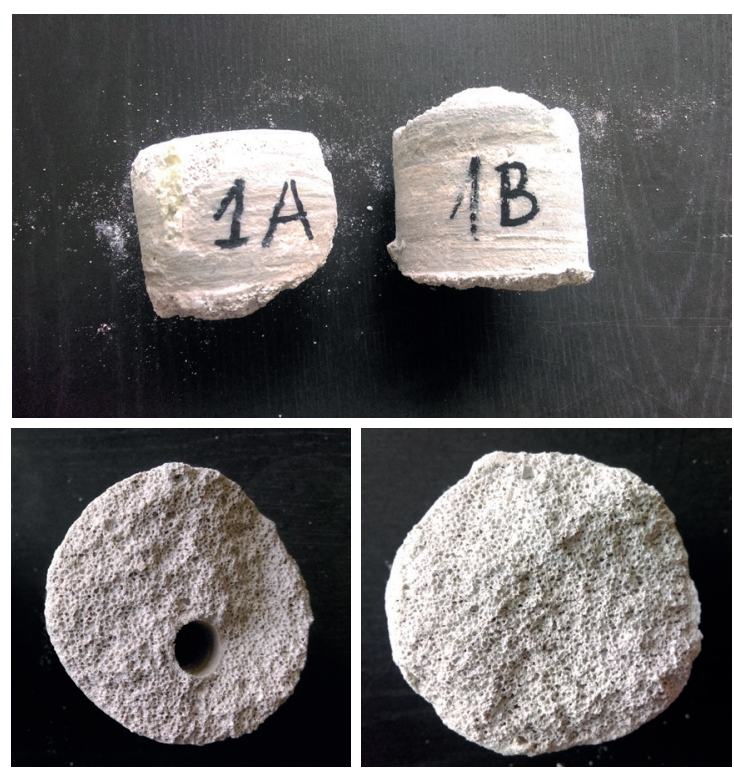

Fig. 3 Samples collected from the research model - May 2017

Inside the model (Fig. 2), a heat source in the form of a $60 \mathrm{~W}$ electric bulb was placed. The temperature and humidity of air were being recorded in the continuous mode both inside and outside the model by means of two Albatronic recorders, model AB-171, which had their own power supply. The preset internal temperature of $20^{\circ} \mathrm{C}$ was maintained by means of the controlled thermostat having the accuracy of $+/-0,5^{\circ} \mathrm{C}$. Most of the time the relative humidity of air oscillated from $41 \%$ to $84 \%$ and reflected the external climate according to PN EN 13877. The correlation between the measurement and the parameters defined in the Standard was at the level of 0.95. The studies were carried out from 05.2016 to 05.2017. The paper presents the part of the research results involving one of the walls insulated with the $15 \mathrm{~cm}$ thick Styrofoam.

\section{Achieved results and discussion}

To determine moisture level in the walls, laboratory tests were carried out. The tests were carried out after the operational period of one year. After the disassembly of the test stand, the samples of cellular concrete were collected for analysis from the places located in the direct vicinity of the mechanical 
Table 1 Averaged results of research studies obtained for 5 samples

\begin{tabular}{lccc}
\hline $\begin{array}{c}\text { Tested } \\
\text { sample }\end{array}$ & $\begin{array}{c}\text { Weight of humid } \\
\text { sample } \\
m_{w, g}\end{array}$ & $\begin{array}{c}\text { Weight of dried } \\
\text { sample } \\
m_{s, g}\end{array}$ & $\begin{array}{c}\text { Relative } \\
\text { (measurement) humidity }\end{array}$ \\
\hline A1 & 59,422 & 40,403 & $w, \%$ \\
B1 & 72,793 & 52,935 & $34,70 \%$ \\
A2 & 41,106 & 27,896 & $37,85 \%$ \\
B2 & 46,961 & 29,017 & $47,35 \%$ \\
\hline
\end{tabular}

connectors (samples A) and from the places of the solid wall away from the connectors (samples B). The samples $1 \mathrm{~A}$ and $1 \mathrm{~B}$ were finished with plaster of low diffusion resistance $\mu=10$, and the samples $2 \mathrm{~A}$ and $2 \mathrm{~B}$ with the plaster of the diffusion resistance factor $\mu=215$. The measurement of water content was carried out using the drying-weighting method. From each place A and place B, 5 samples were collected for analysis.

Before the measurements, the samples were cut to appropriate dimensions. The table presents also the results obtained with the use of the program WUFI 2D. The results of the measurement are presented in Table 1.

To determine the moisture changes of the investigated wall in time, simulation calculations were carried out using the program WUFI 2D. The program is based on a system of nonlinear partial differential equations describing the non-stationary, coupled heat and moisture transport in building materials. The moisture level of particular envelope layers is determined allowing for diffusive flow of water vapour, sorption accumulation of moisture and capillary movement. In the program WUFI 2D, the diffusion of water vapour flux in time $\tau$ is described by the general transport equation in the Cartesian coordinate system $x, y$ as presented in [1]:

$$
\frac{\partial u}{\partial \tau}=\frac{1}{\partial x}\left(D_{w x}(u) \frac{\partial u}{\partial x}+\frac{1}{\partial y}\left(D_{w y}(u) \frac{\partial u}{\partial y}\right)\right.
$$

The equation (1) contains the coefficients of liquid transport in capillary, porous materials marked as $D_{w x}, D_{w y}$. The above coefficients were determined by the authors of the software in an empirical way for definite types of materials and for the normalized content of moisture. In the investigated case $D_{w x}=$ $D_{w y}$. Boundary conditions are defined by means of:

- normalized climatic data for a selected geographical localization (temperature of outdoor air, air humidity, wind speed, intensity of solar radiation, direction and speed of wind, direction and intensity of precipitation), or by means of own measurement data,

- normalized data of indoor climate (temperature and humidity of indoor air), or the data collected from own test stands. The initial conditions are defined by:

- individual initial moisture content of each material of the layer, or by accepting moisture equilibrium conditions offered in the table of material data of the program,

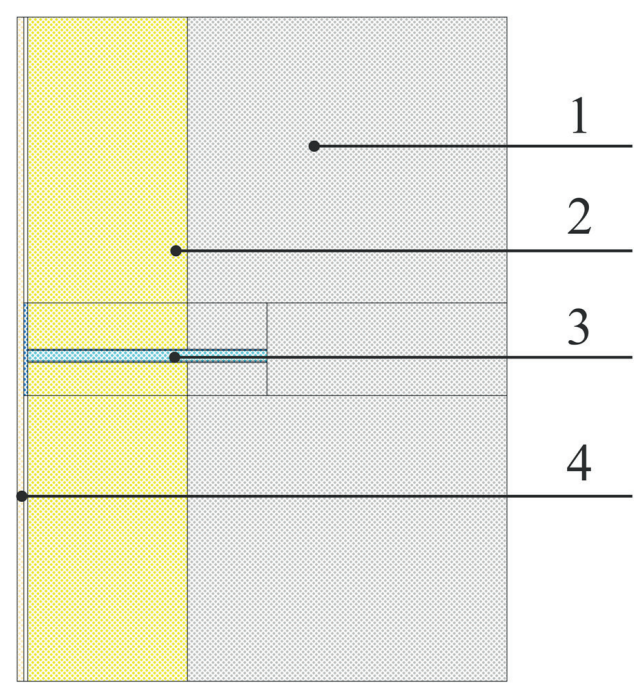

1 - wall from cellular concrete blocks, 2 - thermal insulation, 3 - connector for thermal insulation, 4 - thin-coat external plaster, adhesive with a mesh as in the ETICS system.

Fig. 4 Model of external wall with the embedded metal connector

- providing the date and hour, specifying when the calculations started and finished. For a specific date and hour, automatically normalized data involving outdoor climate and indoor climate are allocated.

In the carried out analysis, the types of materials available in the data base of the program were used in practice. For the calculations, we selected a masonry external wall from cellular concrete with cement-lime mortar, $24 \mathrm{~cm}$ thick, insulated with a Styrofoam layer with thin-coat plaster in the ETICS system. In the envelope, a connector with the metal core of the diameter of $8 \mathrm{~mm}$ was embedded. The total thickness of the connector was $10 \mathrm{~mm}$. The model is presented in Fig.4.

In the hygrothermal calculations, we allowed for the dependence of the thermal conductivity of the material and capillary transport coefficient on its moisture content. It is particularly significant in the case of materials of high absorbency, for which momentary coefficients of thermal conductivity of the material strongly depend on its moisture content. Such a situation takes place in the investigated case of high porosity cellular concrete, for which the value of this coefficient is changing within the range from about 0.2 to $0.7 \mathrm{~W} / \mathrm{mK}$, depending on its moisture content [7].

Before the simulation, initial and boundary conditions were accepted. The initial mass moisture of the cellular concrete wall was defined at $50 \%$. Extremely high initial content of moisture in the cellular concrete results in the rise of its thermal conductivity, which depends on moisture level and on the type of material structure. The walls were insulated with the $15 \mathrm{~cm}$ thick expanded polystyrene EPS 045 of the thermal conductivity calculation factor of $\lambda=0.045 \mathrm{~W} / \mathrm{mK}$ and diffusion resistance coefficient $\mu=30$. The ETICS insulation system was finished with thin mineral plastering of the diffusion resistance coefficient $\mu=10$, and alternatively, for the 
modified silicone plaster $\mu=215$. The combined thickness of the plastering was $0.5 \mathrm{~cm}$. Combined thickness is understood as a layer of adhesive mortar with a mesh and a layer of plaster. As the mechanical connector, we accepted a metal rod of the thermal conductivity coefficient $\lambda=50.0 \mathrm{~W} / \mathrm{mK}$ and diffusion resistance coefficient $\mu=100000$, in the PCV wrapping of $\lambda$ $=0.16 \mathrm{~W} / \mathrm{mK}$ and $\mu=15000$. Other material data, including porosity, density, specific heat were accepted on the basis of information contained in the data base available in the program WUFI 2D. Outdoor climate was simulated on the basis of climate data for the town of Katowice (Poland). In the case of indoor climate, the calculation variants were limited to dry rooms having regular operation mode according to PN EN 13877. In all cases bright colour of the plaster surface layer was accepted. The calculations were carried out for two plastering variants. The plasters of different diffusion resistance coefficient $\mu$ were accepted.

The variants are marked as follows:

$1-$ Styrofoam + plaster with a mesh and adhesive (for the plaster $\mu=10$ ),

2 - Styrofoam + plaster with a mesh and adhesive (for the plaster $\mu=215$ ).

The program WUFI 2D offers a wide range of analyses involving the obtained results. In the present paper, the results were limited to the presentation of moisture changes of the structural material (cellular concrete) in the immediate vicinity of the imperfections (connector for thermal insulation) and at the edges of the model. The investigated areas were marked on the FEM mesh of the analyzed detail and presented in Fig.5.

The analysis carried out on the 2D model involved the following:

- moisture changes of the external plaster, 2D model,

- moisture changes of the structural material of the wall cellular concrete.
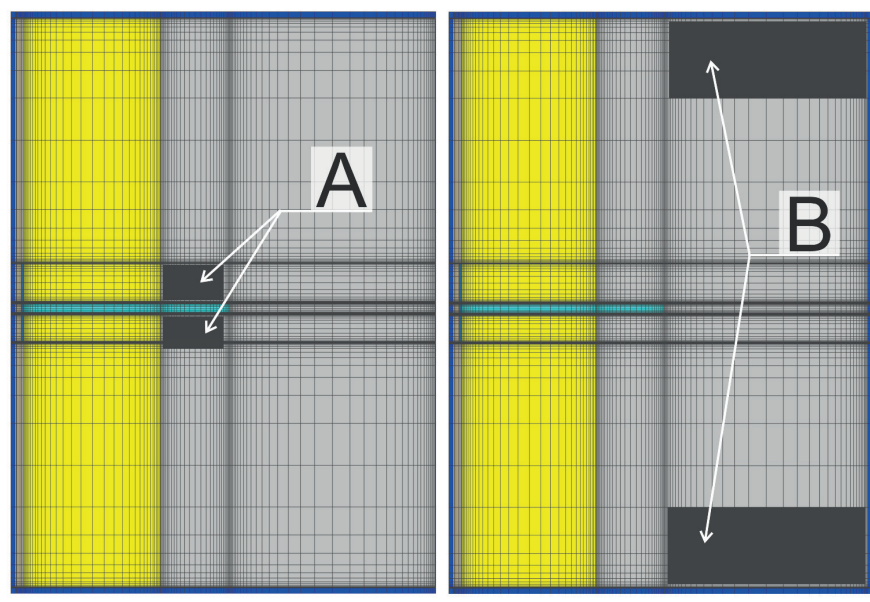

Fig. 5 A FEM mesh. The investigated area in terms of moisture increment at the edge of the model (place B) and the place of insulation connector (place A) - marked with black colour
All calculations were carried out for the research time period of $87690 \mathrm{~h}$ (1 year), for the following initial conditions:

- start of the calculations on the first day 01.05.2016, climate for Katowice,

- initial microclimate $t_{i}=+20 \mathrm{oC}, \varphi_{i}=55 \%$,

- materials in dry-air conditions, except for cellular concrete, where the moisture was accepted at the level of $400 \mathrm{~kg} / \mathrm{m}^{3}$, i.e. $w_{m}=66,6 \%$.

Annual changes of water content in the areas around the connector (place A) and at the cross-section edge (place B) are presented in Figs. 6,7 (variant 1) and in Figs. 8,9 (variant 2).

The calculation results of two-dimensional modeling involving moisture increment (for variant 1) are presented in the graphical form in the three-dimensional coordinate system ("pseudo 3D") over the time of $0 \mathrm{~h}$ and 8760h (1 year) in Fig.7.

The calculation results of two-dimensional modeling involving the increment of moisture for the variant 2 are presented in the graphical form in the tree-dimensional coordinate system ("pseudo 3D") in Fig.9.

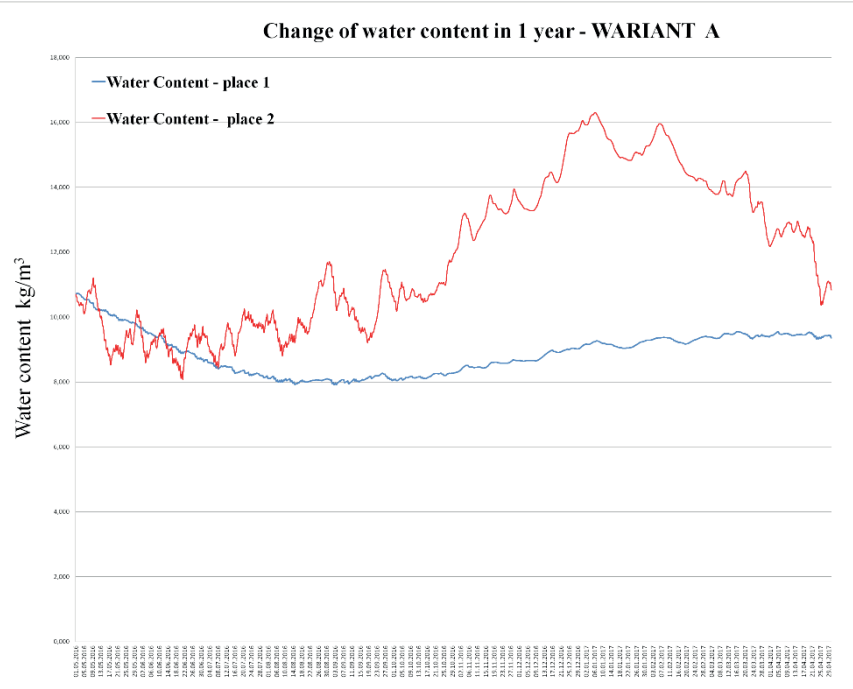

Fig. 6 Change of water content within the area of structural material around the connector and away from the connector over the time of 1 year. Variant 1
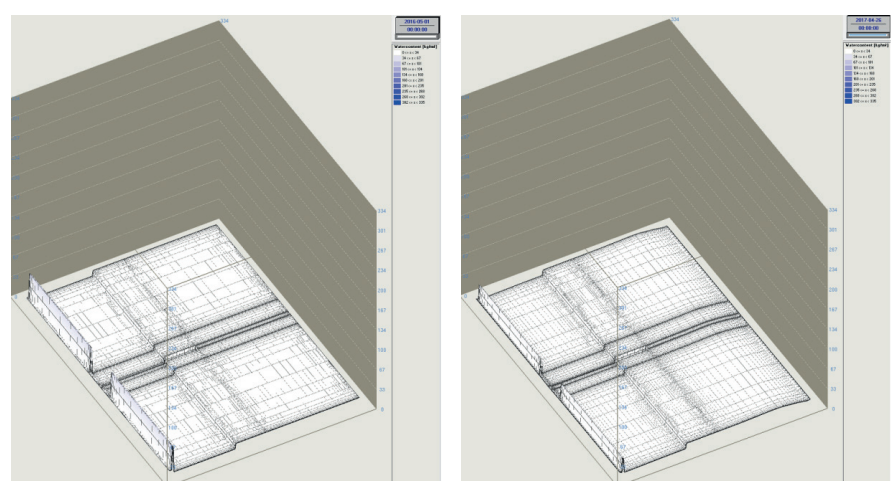

Fig. 7 Calculation results from the program WUFI 2-D. Variant 1 - external plaster $\mu=10$. Envelope model as in Fig. 4 in 3D view. Fig. on the left model after 0 h. Fig. on the right - model after 8760 h (1 year) 


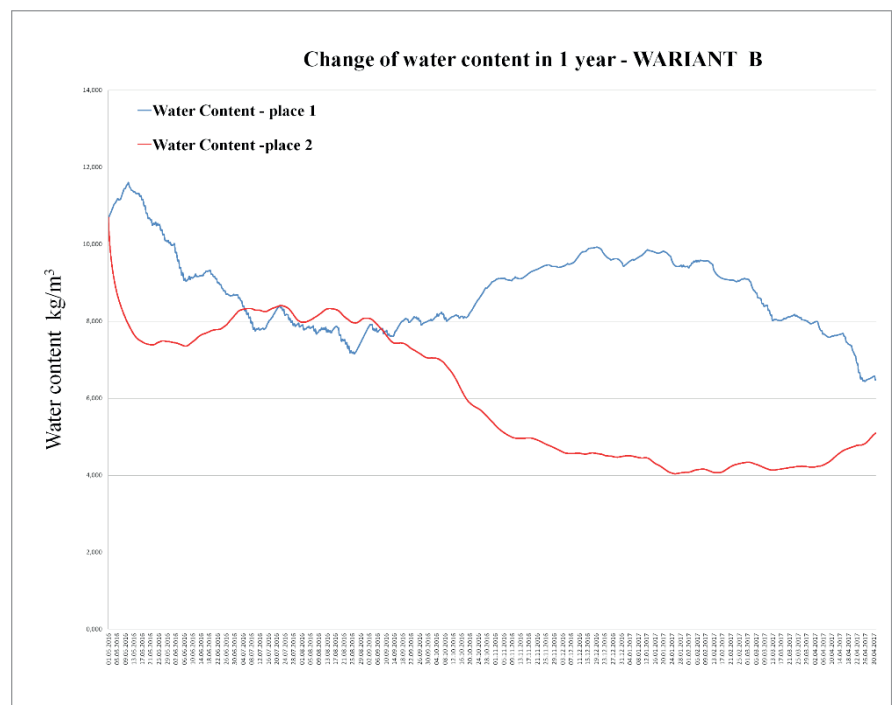

Fig. 8 Change of water content within the area of structural material around the connector and away from the connector over the time of 1 year. Variant 2
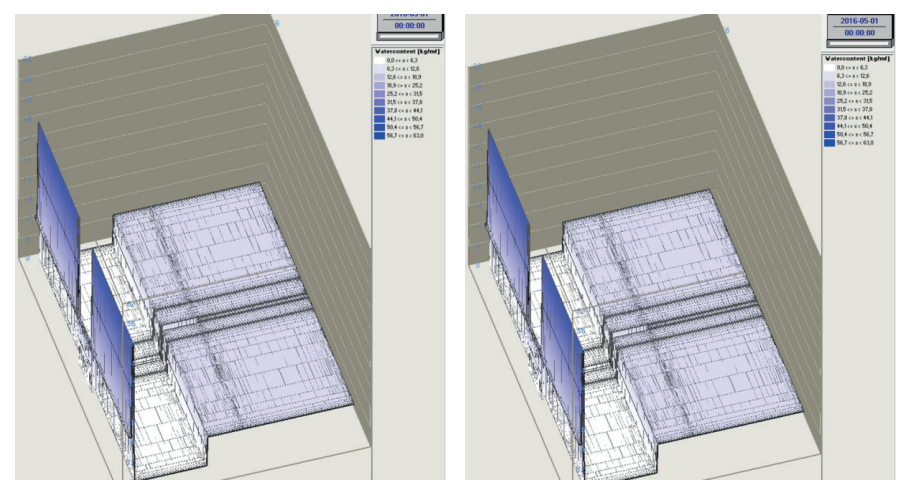

Fig. 9 Calculation results from the program WUFI 2-D. Variant 2 - external plaster $\mu=215$. Envelope model as in Fig. 4 in 3D view. Fig. on the left model after 0 h. Fig. on the right - model after 8760 h (1 year)

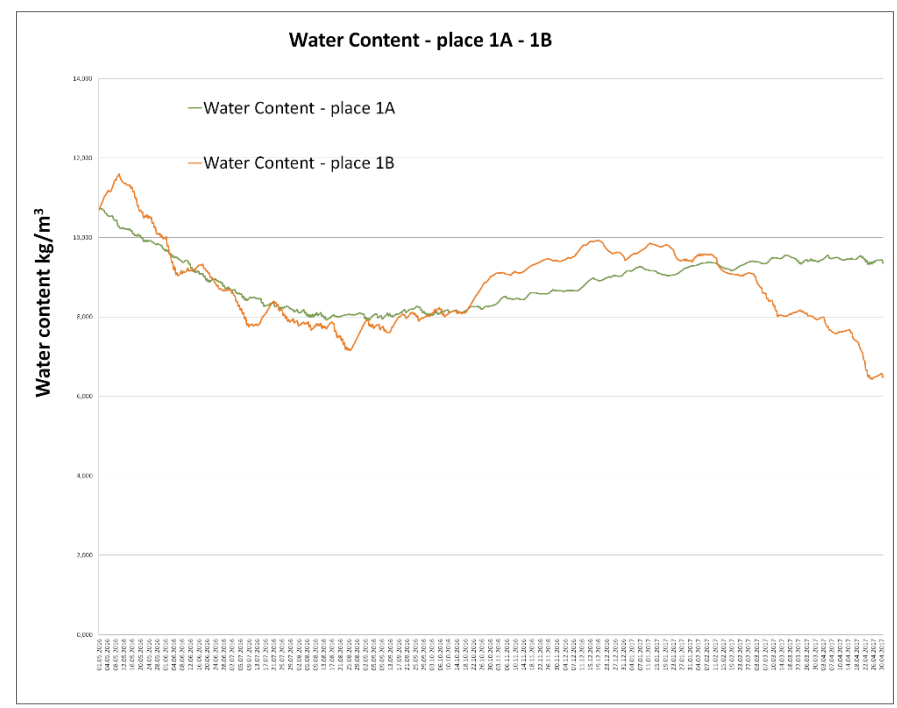

Fig. 10 Simulation results involving the changes of water content over the time of 1 year, in the vicinity of imperfections in the form of insulation connectors (A1 and A2)

Figures 10 and 11 present the analyses involving the changes of water content at the places 1 and 2, depending on the type of applied external plaster.

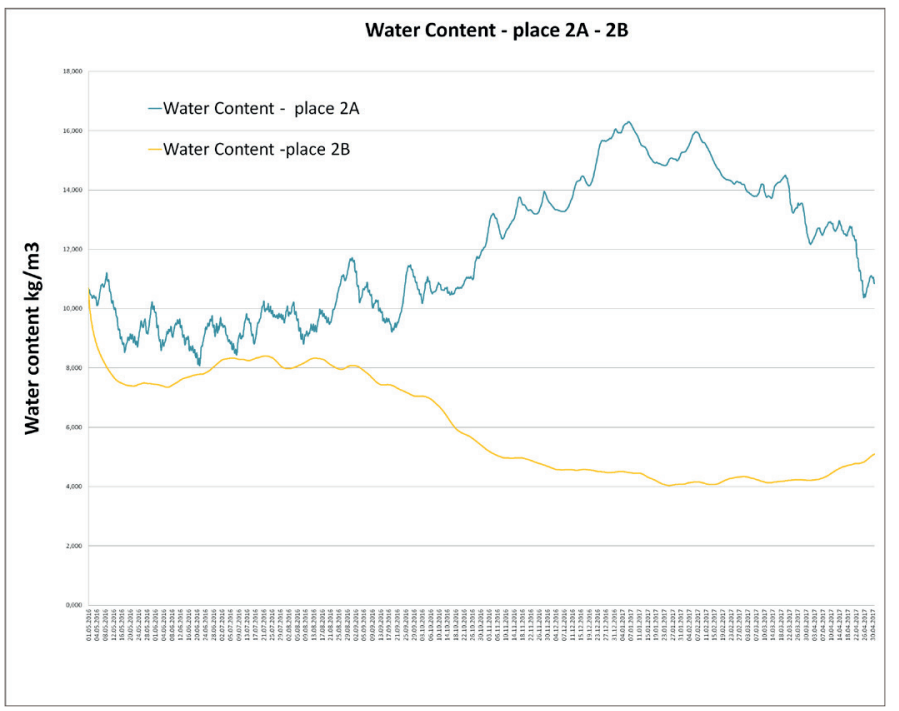

Fig. 11 Simulation results involving the changes of water content over the time of 1 year, away from imperfections in the form of insulation connectors (B1 and B2)

Table 2 Compared results of the research studies and calculations obtained in the program WUFI 2D.

\begin{tabular}{lcc}
\hline $\begin{array}{l}\text { Investigated } \\
\text { sample }\end{array}$ & $\begin{array}{c}\text { Average relative } \\
\text { (measurement) humidity }\end{array}$ & $\begin{array}{c}\text { Relative humidity obtained from } \\
\text { the simulation WUFI 2D }\end{array}$ \\
\hline A1 & $34,70 \%$ & $38,80 \%$ \\
B1 & $37,85 \%$ & $41,36 \%$ \\
A2 & $47,35 \%$ & $51,36 \%$ \\
B2 & $61,50 \%$ & $63,87 \%$ \\
\hline
\end{tabular}

Table 2 presents the results of laboratory tests involving the content of water in cellular concrete compared to the calculation results obtained in the program WUFI $2 \mathrm{D}$ for the time period corresponding with the conditions of the research studies.

\section{Conclusions}

The simulations carried out for a cellular concrete wall insulated with Styrofoam in the ETICS system have demonstrated the following:

- the drying-out model of cellular concrete envelope presented in the literature [7] was confirmed,

- with respect to thermal insulation in the form of Styrofoam, the impact of diffusion resistance coefficient $\mu$ of the external plaster on the obtained results is inconsiderable,

- the drying-out process of the cellular concrete wall in the vicinity of the insulation connector is considerably slower as compared to places located even at small distance from the installed connector (e.g. the distance equal to 20 diameters of the connector). The final water content in the cellular concrete in the vicinity of the steel connector is 1.5 times higher than that at the place located only $20 \mathrm{~cm}$ away from the connector. It bespeaks of small water migration inside the cellular concrete over the operation time,

- high vapour permeability of the plaster at the disruption place has favourable impact on the distribution of water 
content. There are, however, high daily and seasonal differences in moisture level, which results in considerable splotching on the surface of thin-layer plaster at the places of insulation connectors, especially in urban environments,

- in the vicinity of the imperfections (insulation connector) the impact of physical properties of the external plaster on the changes of water content is very low (Fig.10); the said impact is considerable in the remaining part of cellular concrete, outside the imperfection.

- in walls made from cellular concrete and insulated with Styrofoam, it is not recommended to apply steel connectors without any additional protective device (e.g. a cover cap for thermal insulation),

- for all calculations carried out in the program WUFI 2D, convergence coefficients are at the level of (7-5) $10^{-5}$ with the number of iterations being around 1500 , which bespeaks of good convergence of the obtained numerical calculations,

- the compliance of the obtained in-situ research results with the simulation results, with the limited number of samples, should be accepted as good, Table 2).

It should be emphasized that the authors intentionally ignored most of the theoretical issues from point 3 , limiting themselves to the presentation of the basic equation of fluid transport in porous media. Thorough explanation of physical phenomena taking place in cellular concrete, involving the coupled transport of heat and mass was not the objective of the present paper. The said issues can be found in subject literature $[8,10]$. The results involving the moisture level of envelope parts were obtained through the simulation of the coupled processes of heat and mass flow in the specific conditions of external and internal climate and for the accepted initial material characteristics. In order to find out the real performance of envelope materials, further studies should be in each case focused on the impact of imperfections, allowing for befitting local climate conditions and microclimate of the interior.

\section{Critical comments:}

The authors did not consider statistical issues involving the measurement of moisture due to insufficient number of samples collected for analysis. The applied test stand was in part saved for the execution of further studies.

\section{References}

[1] Orlik-Kożdoń, B., Nowoświat, A., Krause, P., Ponikiewski, T. "A numerical and experimental investigation of temperature field in place of anchors in ETICS system". Construction Building Materials, 167, pp. 553-565, 2018.

https://doi.org/10.1016/j.conbuildmat.2018.02.039

[2] Gawin D., Koniorczyk M., Kośny J., Więckowska A. "Effect of moisture on the energy consumption during the initial period of use of a singlefamily house", In: Proc. of VI Scientific and Technological Conf. "Problems of Disigning, Realization and Utilization of Low Energy Consuming Buildings" - ENERGO-DOM. Kraków 2002
[3] Jin, H-Q., Yao, X-L., Fan, L-W., Xu, X., Yu, Z-T. "Experimental determination and fractal modeling of the effective thermal conductivity of autoclaved aerated concrete: Effects of moisture content". International Journal of Heat and Mass Transfer, 92, pp. 589-602. 2016. https://doi.org/10.1016/j.ijheatmasstransfer.2015.08.103

[4] Janssen, H., Scheffler, G. A., Plagge, R. "Experimental study of dynamic effects in moisture transfer in building materials". International Journal of Heat and Mass Transfer, 98, pp. 141-149. 2016.

https://doi.org/10.1016/j.ijheatmasstransfer.2016.03.031

[5] Jerman, M., Keppert, M., Výborný, J., Černý, R. "Hygric, thermal and durability properties of autoclaved aerated concrete". Construction and Building Materials, 41, pp. 352-359. 2013.

https://doi.org/10.1016/j.conbuildmat.2012.12.036

[6] Krause, P. "The numeric calculation of selected thermal bridges in the walls of AAC". (Obliczenia numeryczne wybranych mostków termicznych w ścianach z betonu komórkowego), Cement Wapno Beton, 5, pp. 371-380. 2017.

[7] Künzel, H. M. "Simultaneus Heat and Moisture Transport in Building Components. One and two dimensional calculation using simple parameters", IRB Verlag, Stuttgart 1995. https://www.ibp.fraunhofer.de/content/ dam/ibp/de/documents/Publikationen/Dissertationen/hk_dissertation etcm45-30731.pdf

[8] Le, A. D. T, Maalouf, C., Douzane, O., Promis, G., Mai, T. H., Langlet, T. "Impact of combined moisture buffering capacity of a hemp concrete building envelope and interior objects on the hygrothermal performance in a room". Journal of Building Performance Simulation, 9(6), pp. 589 605. 2016.

https://doi.org/10.1080/19401493.2016.1160434

[9] Nowoświat, A., Skrzypczyk, J., Krause, P., Steidl, T., Winkler-Skalna, A., "Estimation of thermal transmittance based on temperature measurements with the application of perturbation numbers". Heat and Mass Transfer, 54(5), pp. 1477-1489. 2017. https://doi.org/10.1007/s00231-017-2233-y

[10] Litavcova, E., Korjenic, A., Korjenic, S., Pavlus, M., Sarhadov, I., Seman, J., Bednar, T. "Diffusion of moisture into building materials: A model for moisture transport". Energy and Buildings, 68(Part A), pp. 558-561. 2014.

https://doi.org/10.1016/j.enbuild.2013.09.018

[11] Maalouf C., Tran Le, A. D., Umurigirwa, S. B., Lachi, M., Douzane, O. "Study of hygrothermal behaviour of a hemp concrete building envelope under summer conditions in France". Energy and Buildings, 77, pp. 4857. 2014.

https://doi.org/10.1016/j.enbuild.2014.03.040

[12] Narayanan, N., Ramamurthy, K. "Structure and properties of aerated concrete: a review". Cement and Concrete Composites, 22(5), pp. 321-329. 2000 .

https://doi.org/10.1016/S0958-9465(00)00016-0

[13] Orlik-Kożdoń, B., Steidl, T. "Impact of internal insulation on the hygrothermal performance of brick wall". Journal of Building Physics, 41(2), pp. $120-134.2016$

https://doi.org/10.1177/1744259116671322

[14] Šikulaa, O., Mohapl, M. "2D Model of Capillary Transport of Water in Aerated Concrete". Advanced Materials Research, 649, pp. 287-290. 2013.

https://doi.org/10.4028/www.scientific.net/AMR.649.287 